\title{
Prexasertib increases the sensitivity of pancreatic cancer cells to gemcitabine and S-1
}

\author{
YOSHIHITO MORIMOTO $^{1}$, KIMIHIKO TAKADA ${ }^{1}$, OSAMU TAKEUCHI ${ }^{2}$, AKINORI TAKAGI ${ }^{1}$, \\ KAZUHIRO WATANABE ${ }^{1}$, MASAYOSHI HIROHARA ${ }^{1}$, TOMOYUKI HAMAMOTO ${ }^{1}$ and YUTAKA MASUDA ${ }^{1}$ \\ ${ }^{1}$ Center for Education and Research on Clinical Pharmacy, Showa Pharmaceutical University, Tokyo 194-8543; \\ ${ }^{2}$ Biomedical Laboratory, Department of Research, Kitasato Institute Hospital, Tokyo 108-8642, Japan
}

Received February 22, 2019; Accepted September 25, 2019

DOI: $10.3892 /$ or.2019.7421

\begin{abstract}
Our previous study demonstrated that gemcitabine (GEM), S-1, and a combination of GEM and S-1 (GS) induced S-phase arrest and increased the phosphorylation of checkpoint kinase 1 (Chk1), which is a critical mediator of cell survival under impaired DNA replication, in pancreatic cancer cell lines. The aim of the present study was to investigate the combined effect of the Chk1 inhibitor prexasertib and antitumor drugs (GEM and S-1) on pancreatic cancer cell line SUIT-2. Furthermore, we conducted mechanistic analysis of the combined effect. The MTT assay revealed that a combination of prexasertib and GS showed a strong effect. Mechanistic analysis of the combined effect showed effective induction of apoptosis. Furthermore, a combination of prexasertib and GS downregulated the expression of antiapoptotic protein Bcl-2. Chk1 knockdown with small interfering RNA and GS treatment resulted in strong induction of apoptosis. Our results provide evidence to show that the combination of prexasertib and GS has a strong antitumor effect and effectively induces apoptosis in pancreatic cancer cells through downregulation of the antiapoptotic protein Bcl-2. Prexasertib could possibly enhance the effects of standard drugs, including GEM, S-1, and GS, against pancreatic cancer.
\end{abstract}

Correspondence to: Mr. Yoshihito Morimoto, Center for Education and Research on Clinical Pharmacy, Showa Pharmaceutical University, 3-3165 Higashi-Tamagawagakuen, Machida, Tokyo 194-8543, Japan E-mail: y-morimoto@ac.shoyaku.ac.jp

Abbreviations: GEM, gemcitabine; GS, GEM + S-1; Chk1, checkpoint kinase 1; 5-FU, 5-fluorouracil; FT, tegafur; CDHP, 5-chloro-2,4-dihydroxypyridine; Oxo, oteracil potassium; DPD, dihydropyrimidine dehydrogenase; OS, overall survival; HR, hazard ratio; Chk2, checkpoint kinase 2; MTT, 3-(4,5-dimethylthiazol-2-yl)-2,5-diphenyltetrazolium bromide; PBS, phosphate-buffered saline; siRNA, small interfering RNA; GC, GEM and cisplatin

Key words: prexasertib, gemcitabine, S-1, pancreatic cancer, apoptosis, Chk1, Bcl-2

\section{Introduction}

Pancreatic cancer is a highly malignant carcinoma characterized by a dismal patient prognosis; therefore, the development of more effective treatments is urgently required. Gemcitabine (GEM) has been used worldwide as a key agent for chemotherapy for the treatment of pancreatic cancer after it was reported that it significantly prolonged overall survival in a phase III trial compared with 5-fluorouracil (5-FU) (1). S-1 (TS-1; Taiho Pharmaceutical Co., Ltd., Tokyo, Japan), an oral fluoropyrimidine developed in Japan, consists of tegafur (FT), 5-chloro-2,4-dihydroxypyridine (CDHP), and oteracil potassium (Oxo) at a molar ratio of 1:0.4:1 (2). FT is a prodrug of 5-FU and is catabolized by dihydropyrimidine dehydrogenase (DPD) $(3,4)$. CDHP competitively inhibits DPD, and thereby maintains effective concentrations of 5-FU in both plasma and tumor tissues (5). Oxo inhibits phosphorylation of 5-FU in the gastrointestinal tract, thereby reducing the gastrointestinal toxicity of 5-FU (6). The antitumor effect of S-1 has already been demonstrated in a single agent or combination regimen against a variety of solid tumors, such as gastric cancer, colorectal cancer and non-small cell lung cancer (7-11). Regarding pancreatic cancer, a randomized phase III trial of GEM and S-1 monotherapy and GEM + S-1 combination (GS) therapy for pancreatic cancer with locally advanced or distant metastases (GEST) has shown that S-1 was not inferior to GEM. The GEM therapy group had a median overall survival (OS) of 8.8 months and the S-1 therapy group had a median OS of 9.7 months [hazard ratio (HR) 0.96] (12). Although the superiority of GS therapy (10.1 months median OS) to GEM therapy was not verified, GS significantly prolonged the progression-free survival of secondary endpoints compared with GEM and in a subgroup analysis, GS significantly prolonged the OS compared with GEM in locally advanced pancreatic cancer. For adjuvant chemotherapy for pancreatic cancer after resection, a phase III trial of GEM and S-1 therapy has shown that the median OS at the time of the 5-year follow-up between April 2007 and January 2016 was 46.5 months in the S-1 group and 25.5 months in the GEM group, and the HR of the S-1 group vs. the GEM group was 0.57 (0.44-0.72), indicating S-1 therapy was superior to GEM therapy $(\mathrm{P}<0.0001$; log-rank test) (13). On the basis of these trials, GEM and S-1 are recognized as key drugs for pancreatic cancer in Japan. 
Our previous research using pancreatic cancer cells showed that a combination of S- 1 and GEM is more effective than either drug alone, both in vitro and in vivo. Moreover, a combination of S-1 and GEM induced a greater degree of S-phase arrest than either agent alone $(14,15)$. Mechanistic studies showed that both drugs led to increased phosphorylation of checkpoint kinase 1 (Chk1). Chk1 is activated when DNA is damaged, when it stops the cell cycle and catalyzes DNA repair (16). Therefore, it is expected that after the induction of DNA damage with antitumor drugs in combination with a Chk1 inhibitor, DNA damage checkpoints are inactivated and eventually cause cell death in a more potent manner. Several Chk1 inhibitors have been developed and clinical trials have been conducted for both monotherapy or combination treatments with antitumor drugs (17-22). Prexasertib (LY2606368) is one of the inhibitors of Chk1 and checkpoint kinase 2 (Chk2) and inhibits Chk1 more strongly than Chk 2 by causing DNA double-strand breaks and apoptosis when used as a single agent (23).

The aim of the present study was to investigate the combined effect of the Chk1 inhibitor prexasertib with GEM, S-1, and GS on the pancreatic cancer cell line SUIT-2. Moreover, we conducted further mechanistic analysis of the combined effects.

\section{Materials and methods}

Cell cultures. The human pancreatic cancer cell line SUIT-2 was obtained from the Japanese Collection of Research Bioresources (Osaka, Japan). SUIT-2 cells were grown in RPMI-1640 medium (FUJIFILM Wako Pure Chemical Corp., Osaka, Japan) supplemented with $10 \%$ fetal bovine serum (FBS), penicillin, and streptomycin.

Antitumor agents. GEM, 5-FU, and CDHP were purchased from Tokyo Chemical Industry Co., Ltd. (Tokyo, Japan), and prexasertib was purchased from Selleck Biotech (Osaka, Japan).

Antibodies. Monoclonal antibodies against phosphorylated-Chk1 (Ser296) (product \#90178, 1:1,000 dilution), phosphorylated-Chk1 (Ser317) (product \#12302, 1:1,000 dilution), phosphorylated-Chk1 (Ser345) (product \#2348, 1:1,000 dilution), Chk1 (product \#2360, 1:1,000 dilution), $\gamma \mathrm{H} 2 \mathrm{AX}$ (Ser139) (product \#9718, 1:1,000 dilution), H2AX (product \#2595, 1:1,000 dilution), caspase 9 (product \#9508, 1:1,000 dilution), caspase 3 (product \#9665, 1:1,000 dilution), cleaved PARP (Asp214) (product \#5625, 1:1,000 dilution), Mcl-1 (product \#94296, 1:1,000 dilution), Bcl-2 (product \#2870, 1:1,000 dilution), Bcl-xL (product \#2764, 1:1,000 dilution) and Bax (product \#2772, 1:1,000 dilution) were purchased from Cell Signaling Technology. The monoclonal antibody against $\beta$-actin was purchased from Sigma-Aldrich (Merck KGaA, 1:5,000 dilution). Purified mouse anti-cytochrome $c$ (cat. no. 556433, 1:1,000 dilution) was purchased from BD Biosciences.

Cell proliferation assay. Cells were seeded in $96-$ well plates at a density of $1 \times 10^{3}$ cells/well. After $24 \mathrm{~h}$, the culture medium was replaced with $0.2 \mathrm{ml}$ of fresh medium containing GEM, S-1, and/or prexasertib at each concentration. After a further $72 \mathrm{~h}$, $20 \mu 1$ of 3-(4,5-dimethylthiazol-2-yl)-2,5-diphenyltetrazolium bromide (MTT) reagent (Sigma-Aldrich; Merck KGaA) 0.5\% in phosphate buffered saline (PBS) was added to each well. The plate was then incubated for $4 \mathrm{~h}$, and $0.1 \mathrm{ml}$ of dimethyl sulfoxide (Kanto Chemical Co. Inc., Tokyo, Japan) was added to each well to dissolve the formazan crystals. Absorbance was then measured in each well using a microplate reader at a wavelength of $620 \mathrm{~nm}$. Inhibitory concentration $\left(\mathrm{IC}_{50}\right)$ values were then calculated. A classical isobologram was used to evaluate the synergistic effects of GEM + prexasertib and $\mathrm{S}-1+$ prexasertib (24). The combination index (CI) was calculated using CalcuSyn (Biosoft, Cambridge, UK) and synergy level classifications were determined. A CI $<1$ indicates synergy, a $\mathrm{CI}=1$ indicates additive effects, and a $\mathrm{CI}>1$ indicates antagonistic effects. All experiments were repeated at least three times.

Analysis of cell death. Cells were seeded on 6-well plates (6.0x $10^{4}$ cells/well) in RPMI-1640 medium supplemented with $10 \%$ FBS. After $24 \mathrm{~h}$, the culture medium was replaced with $2.0 \mathrm{ml}$ of fresh medium containing GEM $(0.3 \mathrm{ng} / \mathrm{ml})$, S-1 $(0.2 \mu \mathrm{g} / \mathrm{ml})$, and/or prexasertib $(5 \mathrm{nM})$. After a further $72 \mathrm{~h}$, mono- and oligonucleosomes in the cytoplasmic fraction were measured by the Cell Death Detection ELISA kit (Roche Diagnostics, Basel, Switzerland; cat. no. 1544675) according to the manufacturer's instructions. Floating and attached cells were collected and homogenized in $500 \mu \mathrm{l}$ of incubation buffer. The wells of a 96-well plate were coated with antihistone antibodies at room temperature for $1 \mathrm{~h}$ and incubated with the lysates, horseradish peroxidase-conjugated anti-DNA antibodies, and the substrate, and the absorbance was read at $405 \mathrm{~nm}$. Furthermore, after $72 \mathrm{~h}$ of culture on a 6-well plate under the same conditions, apoptotic cells were assessed by examining their nuclear morphology under a fluorescence microscope after staining with $1.2 \mathrm{mM}$ Hoechst 33342 for $5 \mathrm{~min}$.

Western blot analysis. Cells $\left(3.0 \times 10^{5}\right)$ were seeded in dishes and cultured for $24 \mathrm{~h}$. The medium was replaced by fresh medium containing the drugs (GEM $0.3 \mathrm{ng} / \mathrm{ml}, \mathrm{S}-10.2 \mu \mathrm{g} / \mathrm{ml}$, or prexasertib $10 \mathrm{nM}$ ) and the cells were incubated for the indicated times (24, 48, and $72 \mathrm{~h}$ ). Cells were rinsed with PBS and scraped into cell lysis buffer M (FUJIFILM Wako Pure Chemical Corp.) dissolved in complete protease inhibitor cocktail (Roche) and PhosSTOP phosphatase inhibitor cocktail (Roche). After incubation on ice for $20 \mathrm{~min}$, cell lysates were obtained by centrifugation at $15,000 \mathrm{xg}$ for $15 \mathrm{~min}$ at $4^{\circ} \mathrm{C}$. Protein concentrations were determined and equal amounts $(30 \mu \mathrm{g})$ of total protein were separated on $7.5-12 \%$ sodium dodecyl sulfate polyacrylamide gels at a constant current of $30 \mathrm{~mA}$. Separated proteins were then transferred to Immobilon polyvinylidene difluoride membranes (Millipore) at $150 \mathrm{~mA}$. The membranes were blocked with $1 \%$ Difco $^{\mathrm{TM}}$ skim milk (BD Biosciences) and hybridized overnight at $4^{\circ} \mathrm{C}$ with various primary antibodies. Membranes were then probed with a horseradish peroxidase-conjugated anti-rabbit or anti-mouse antibody (Dako Denmark A/S, Glostrup, Denmark; cat. nos. P0448 or P0260) and chemiluminescence was developed using a SuperSignal West Pico Chemiluminescent Substrate 
(Thermo Fisher Scientific, Inc.). The band intensities of Bcl-2 and $\beta$-actin were analyzed using Image $\mathrm{J} 1.41$ (National Institutes of Health, Bethesda, MD, USA).

Analysis of the release of cytochrome c. Cells $\left(3.0 \times 10^{5}\right)$ were seeded in dishes and cultured for $2 \mathrm{~h}$. The medium was replaced with fresh medium containing the drugs (GEM $0.3 \mathrm{ng} / \mathrm{ml}, \mathrm{S}-10.2 \mu \mathrm{g} / \mathrm{ml}$, or prexasertib $10 \mathrm{nM}$ ) and the cells were incubated for the indicated time $(24,48$, and $72 \mathrm{~h})$. Cells were washed with PBS and treated with $0.05 \%$ trypsin, and then resuspended in $100 \mu \mathrm{l}$ of ice-cold digitonin lysis buffer (0.01\% digitonin in PBS). After 5 min on ice, the cells were centrifuged at $14,000 \mathrm{x}$ for $5 \mathrm{~min}$, and the supernatant was subjected to western blot analysis with cytochrome $c$-specific antibody.

Small interfering RNAs and transfection of cells. Silencer ${ }^{\circledR}$ Select Validated siRNA (small interfering RNA) against Chk1 and Silencer ${ }^{\circledR}$ Select Negative Control siRNA were purchased from Thermo Fisher Scientific, Inc. The day before siRNA transfection, the cells $\left(1 \times 10^{5}\right)$ were seeded into 6-well plates and incubated overnight at $37^{\circ} \mathrm{C}$ without antibiotics. Cells were then treated with siRNA (final concentration of $25 \mathrm{nM}$ ) in RPMI-1640 medium in the presence of the DharmaFECT transfection reagent according to the manufacturer's instructions (GE Healthcare Japan, Tokyo, Japan). After incubation for $24 \mathrm{~h}$ at $37^{\circ} \mathrm{C}$, the medium containing the mixture of DharmaFECT and siRNA was replaced by RPMI-1640 medium containing 10\% FBS and cells were incubated for a further $24 \mathrm{~h}$ with or without the drugs (GEM $0.8 \mathrm{ng} / \mathrm{ml}, \mathrm{S}-1$ $0.5 \mu \mathrm{g} / \mathrm{ml})$.

Statistical analysis. Data from the MTT assays, ELISA and western blot analyses are expressed as the mean \pm standard deviation. Differences between the groups were examined for statistical significance using analysis of variance (ANOVA) followed by Fisher's protected least significant difference analysis. A P-value of $<0.05$ was considered statistically significant. Statistical analysis was performed using a BellCurve created in Excel for Windows (Social Survey Research Information Co., Ltd., Tokyo, Japan).

\section{Results}

Combinations of prexasertib and antitumor drugs (GEM or $S-1)$ exhibit a synergistic antiproliferative effect on SUIT-2 cells. An MTT assay was used to investigate whether prexasertib and an antitumor drug (GEM or S-1) exhibit synergistic effects on the inhibition of cell growth in SUIT-2 cells. S-1 is a combination drug comprising three compounds, but in our study, we omitted the Oxo component (Oxo is used to reduce the incidence of gastrointestinal side effects) and instead used a combination of 5-FU and CDHP at a ratio of 1:2 based on the blood concentration ratio of the combination in humans (25). First, we calculated the $\mathrm{IC}_{50}$ values for each drug. The $\mathrm{IC}_{50}$ values for prexasertib, GEM, and $\mathrm{S}-1$ were $30.8 \pm 6.04 \mathrm{nM}$, $0.642 \pm 0.048 \mathrm{ng} / \mathrm{ml}$ and $0.506 \pm 0.219 \mu \mathrm{g} / \mathrm{ml}$, respectively. Simultaneous administration of various concentrations of prexasertib and an antitumor drug (GEM or S-1) resulted in greater inhibition of SUIT-2 cell growth (Fig. 1A and B). The
Table I. Combination indexes (CI) calculated for the combination of prexasertib + GEM or prexasertib $+\mathrm{S}-1$ (CI $<1$ indicates synergy).

\begin{tabular}{lccc}
\hline & \multicolumn{3}{c}{ Prexasertib (nM) } \\
\cline { 2 - 4 } & 10 & 20 & 30 \\
\hline GEM (ng/ml) & & & \\
0.1 & $0.488^{\mathrm{a}}$ & $0.564^{\mathrm{a}}$ & $0.679^{\mathrm{a}}$ \\
0.3 & $0.456^{\mathrm{a}}$ & $0.584^{\mathrm{a}}$ & $0.723^{\mathrm{a}}$ \\
0.5 & $0.495^{\mathrm{a}}$ & $0.653^{\mathrm{a}}$ & $0.793^{\mathrm{a}}$ \\
$\mathrm{S}-1(\mu \mathrm{g} / \mathrm{ml})$ & & & \\
0.1 & 3.016 & $0.807^{\mathrm{a}}$ & $0.749^{\mathrm{a}}$ \\
0.2 & 1.007 & $0.702^{\mathrm{a}}$ & $0.753^{\mathrm{a}}$ \\
0.3 & $0.820^{\mathrm{a}}$ & $0.661^{\mathrm{a}}$ & $0.716^{\mathrm{a}}$ \\
\hline
\end{tabular}

GEM, gemcitabine. ${ }^{a}$ Indicates synergy.

$\mathrm{IC}_{50}$ values of prexasertib + GEM and prexasertib + S-1 were connected using a dotted line in a classical isobologram to evaluate any possible synergistic effects (Fig. 1C and D). The data revealed that each of these drugs had a synergistic effect, and a combination of prexasertib and GEM had a stronger synergistic effect than prexasertib and S-1 in the SUIT-2 cells. The combination index also demonstrated that the combined effect of prexasertib + GEM and prexasertib + S-1 on cell viability was synergistic $(\mathrm{CI}<1)$ for many concentration combinations (Table I). We further investigated the effect of the combination of all three drugs [prexasertib + GEM + S-1 (GS)]. Prexasertib + GS showed significantly greater inhibition of cell proliferation than prexasertib + GEM or prexasertib + S-1 ( $\mathrm{P}<0.05)$ (Fig. 2A and B).

Induction of apoptosis by prexasertib $+[G E M+S-1(G S)]$. We also investigated apoptotic cell death in SUIT-2 cells using a Cell Death Detection ELISA kit (Roche). This kit includes mouse monoclonal antibodies directed against DNA and histones and allows the specific determination of mono- and oligonucleosomes in the cytoplasmic fraction of cell lysates. Assays using the ELISA kit confirmed that the treatment of SUIT-2 cells with prexasertib at $5 \mathrm{nM}+\mathrm{GS}$ significantly increased the extent of apoptotic cell death compared with the other groups $(\mathrm{P}<0.05)$ (Fig. 3A). In addition, the absorbance for prexasertib at $10 \mathrm{nM}$ with GS was $2.26 \pm 0.14$, which was an approximately 2 -fold increase compared to prexasertib at $5 \mathrm{nM}$ with GS. Fig. 3B shows morphological changes in SUIT-2 cells treated with several drugs for $72 \mathrm{~h}$. The cells treated with prexasertib + GS developed apoptotic features including nuclear fragmentation.

Effect of prexasertib + GS on Chkl signaling and apoptotic pathways. We performed western blotting to measure the change in signals from apoptosis due to the combination of prexasertib + GS. We used prexasertib at $10 \mathrm{nM}$, which induced apoptosis in combination with GS more efficiently than at $5 \mathrm{nM}$ in our pilot experiments. To examine the phosphorylation of the DNA damage-induced cell cycle checkpoint 
A

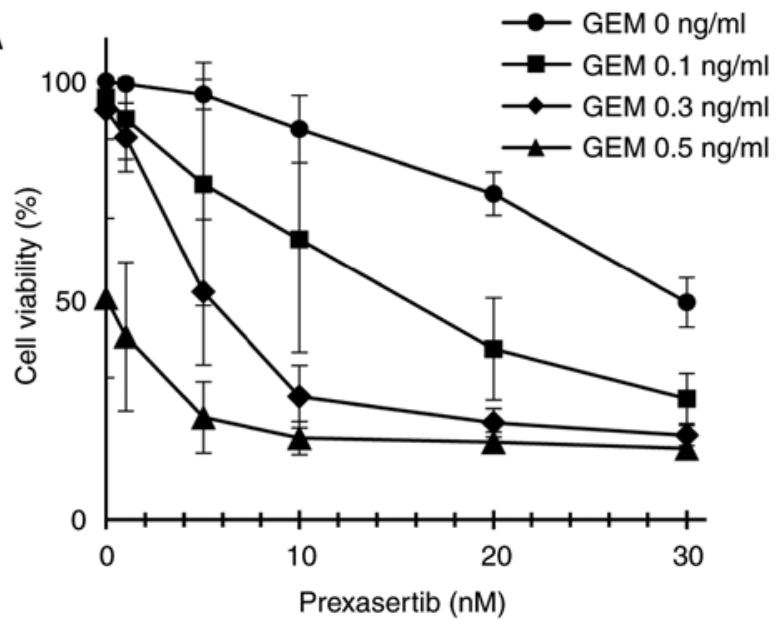

C

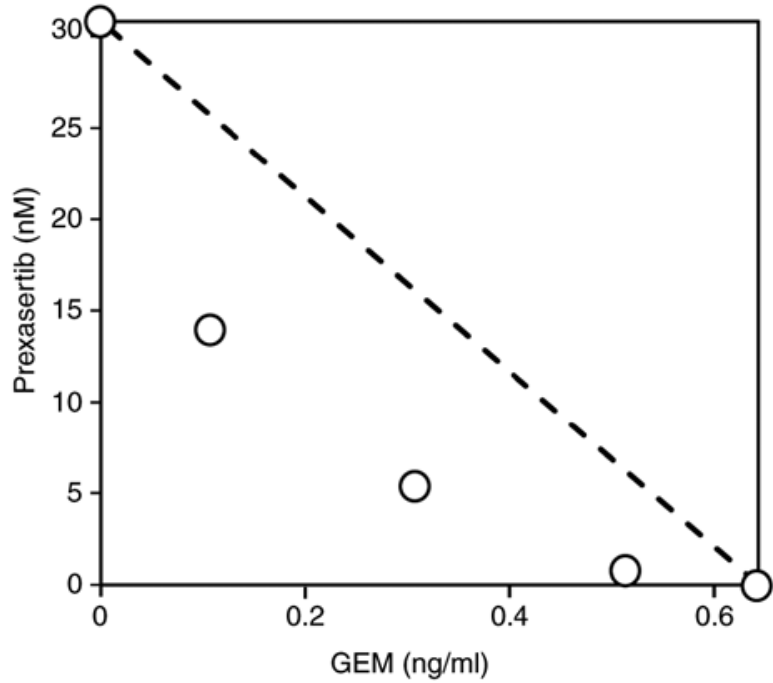

B

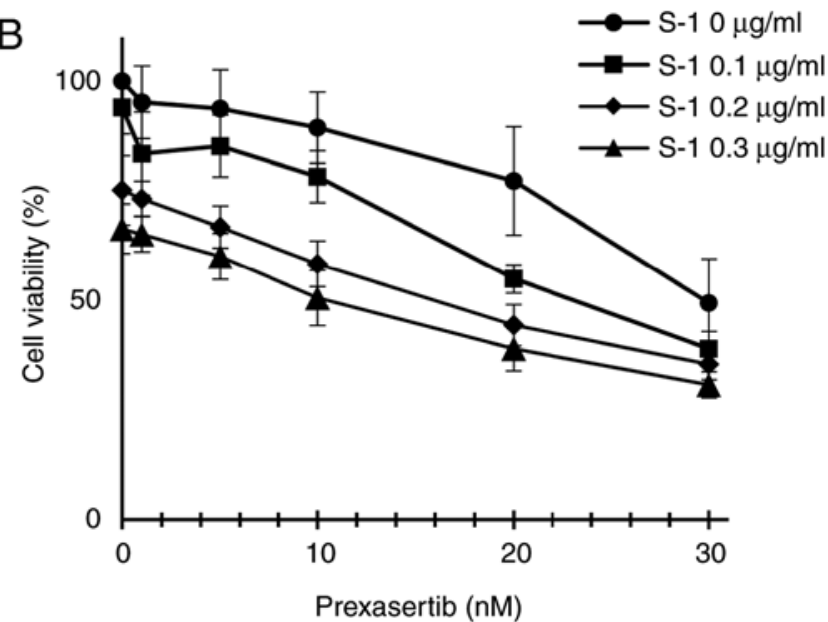

D

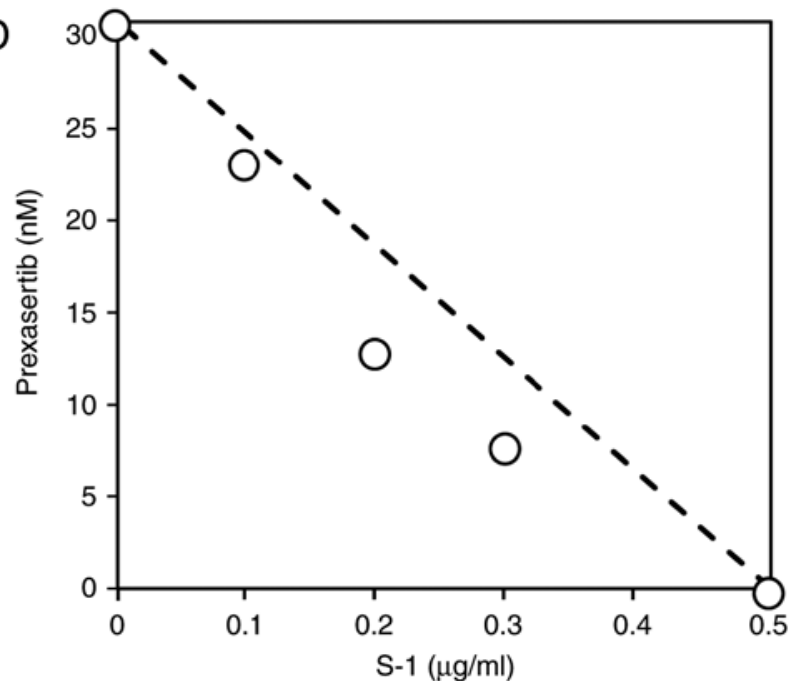

Figure 1. Prexasertib enhanced the antitumor effect of (A) GEM and (B) S-1. SUIT-2 cells were treated with a combination of prexasertib (0, 1, 5, 10, 20, or $30 \mathrm{nM})$ and $\operatorname{GEM}(0,0.1,0.3$, or $0.5 \mathrm{ng} / \mathrm{ml})$, or S-1 $(0,0.1,0.2$, or $0.3 \mu \mathrm{g} / \mathrm{ml})$ for $72 \mathrm{~h}$. Values shown are the mean \pm standard deviation $(\mathrm{SD})$ from at least 3 independent experiments. A classical isobologram shows the combined effect of $(\mathrm{C})$ prexasertib $+\mathrm{GEM}$ and (D) prexasertib $+\mathrm{S}-1$ in $\mathrm{SUIT}-2 \mathrm{cells}$. The IC ${ }_{50}$ values for prexasertib $(30.8 \mathrm{nM})$ and GEM $(0.642 \mathrm{ng} / \mathrm{ml})$, as well as those for prexasertib and S-1 $(0.506 \mu \mathrm{g} / \mathrm{ml})$, are connected with a dotted line to distinguish the area of synergism (under the line) and the area of antagonism (above the line). Plots on the dotted line indicate an additive effect. Both prexasertib + GEM and prexasertib + S-1 showed a synergistic effect. GEM, gemcitabine.

protein Chk1, western blotting was used to assess the levels of phosphorylated Chk1 (pS296, pS317, and pS345) in the SUIT-2 cells (Fig. 4A). Prexasertib suppressed the phosphorylation of Chk1 pS296, which is an autophosphorylation site and most important for the activation of Chk1, at $24 \mathrm{~h}$. Prexasertib + GS increased the phosphorylation of Chk1 pS317 and Chk1 pS345, which are DNA damage markers. The expression of $\gamma \mathrm{H} 2 \mathrm{AX}$, which is also a DNA damage marker, was also induced to a higher degree following prexasertib + GS treatment. However, the expression of total $\mathrm{H} 2 \mathrm{AX}$ did not correlate with the expression of $\gamma \mathrm{H} 2 \mathrm{AX}$. We investigated the apoptotic mechanism induced by prexasertib + GS. The expression levels of cleaved caspase 3 and cleaved PARP were increased at $48 \mathrm{~h}$ (Fig. 4B). We also investigated the effect of prexasertib + GS on the Bcl-2 family. Cleaved Mcl-1 was increased after $48 \mathrm{~h}$ of prexasertib + GS treatment and Bcl-2 was markedly decreased at $24 \mathrm{~h}$; this effect was prolonged until after $72 \mathrm{~h}$ (Fig. 4C). We next examined the effects of prexasertib + GS on the release of cytochrome $c$ from mitochondria in SUIT-2 cells. When the cells were exposed to prexasertib + GS, a significant increase in the release of cytochrome $c$ was observed within $48 \mathrm{~h}$ (Fig. 4D). These results suggest a correlation between the release of cytochrome $c$ and the induction of apoptosis by prexasertib + GS. The expression of Bcl-2 at $72 \mathrm{~h}$ was significantly decreased by prexasertib + GS $(\mathrm{P}<0.05)($ Fig. 4E).

Effects of Chkl-specific siRNA on combination treatment with $G E M$ and $S$-1. It is important to investigate whether prexasertib enhances the combination of GEM and S-1 activity through Chk1 inhibition. We used siRNA to selectively deplete Chk1 in the cells to investigate Chk1 inhibition and its contribution to the effect of GEM and S-1 combined treatment (GS). After transfection, the levels of expression of Chk1 were analyzed by western blotting (Fig. 5A). As shown in Fig. 5A, treatment of SUIT-2 cells with Chk1 siRNA (Chk1-si) significantly suppressed the expression of Chk1 compared with cells treated with non-silencing siRNA (Control-si) or with vehicle alone. Compared with the Control-si (nonspecific siRNA)-transfected cells treated with GS, the Chk1-si cells treated with GS showed significantly higher levels of apoptosis 


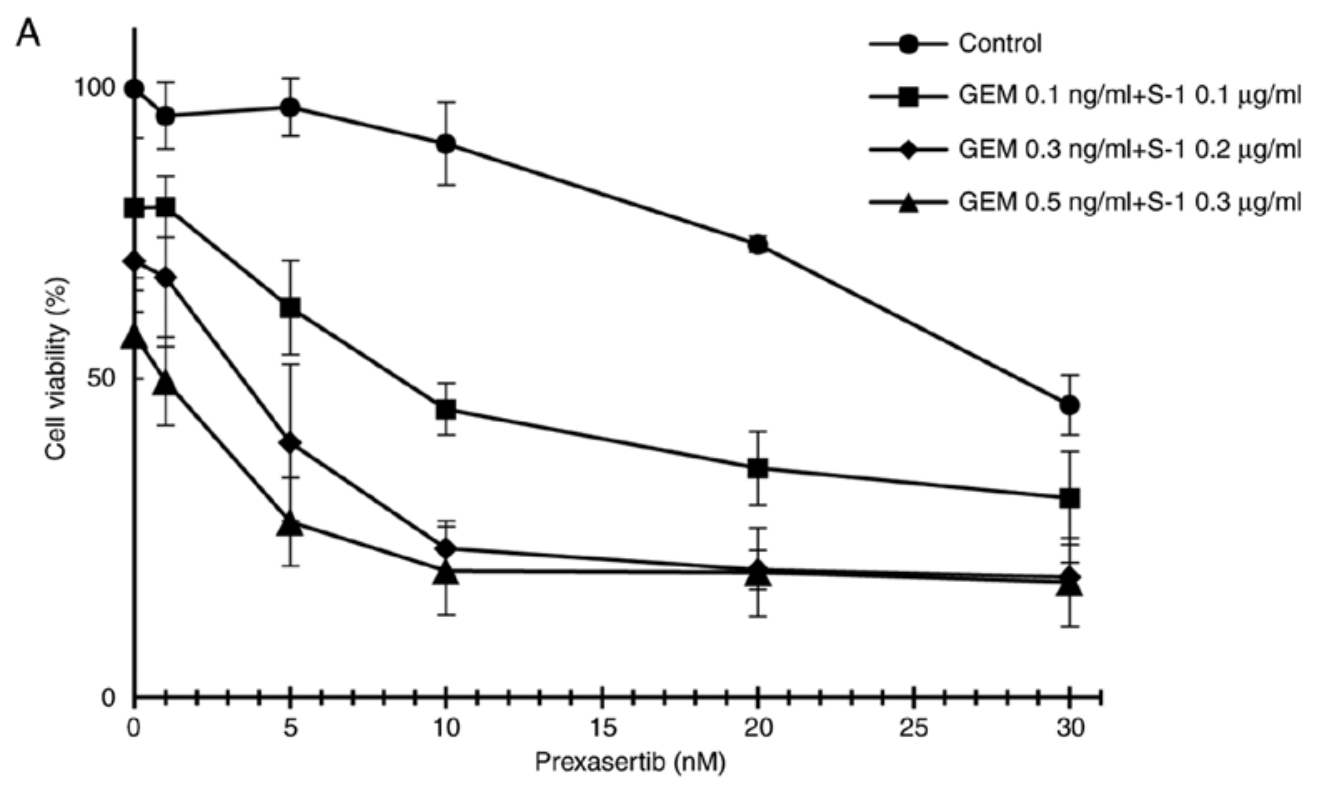

B
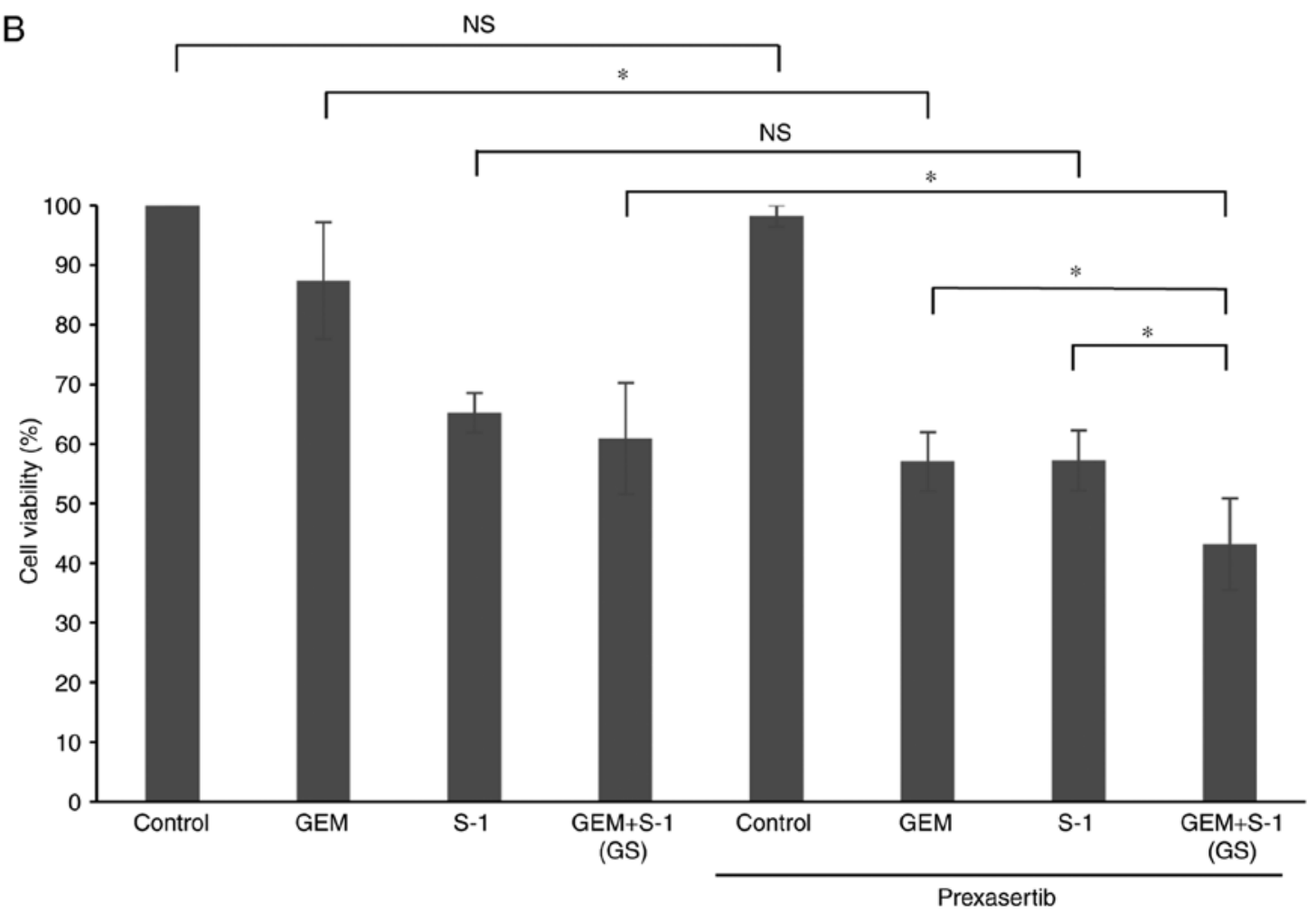

Figure 2. Prexasertib + GEM + S-1 inhibit cell proliferation. (A) SUIT-2 cells were treated with prexasertib $(0,1,5,10,20$, or $30 \mathrm{nM})$ and GEM + S-1 $($ GEM $0.1 \mathrm{ng} / \mathrm{ml}+\mathrm{S}-10.1 \mu \mathrm{g} / \mathrm{ml}$, GEM $0.3 \mathrm{ng} / \mathrm{ml}+\mathrm{S}-10.2 \mu \mathrm{g} / \mathrm{ml}$, or GEM $0.5 \mathrm{ng} / \mathrm{ml}+\mathrm{S}-10.3 \mu \mathrm{g} / \mathrm{ml}$ ) for $72 \mathrm{~h}$. (B) SUIT-2 cells were treated with prexasertib (5 nM) and/or GEM $0.3 \mathrm{ng} / \mathrm{ml}$ and/or S-1 $0.2 \mu \mathrm{g} / \mathrm{ml}$ for $72 \mathrm{~h}$. Values shown are the mean \pm SD from 3 independent experiments. ${ }^{*} \mathrm{P}<0.05$ indicates a significant difference. NS, not significant; GEM, gemcitabine.

at $24 \mathrm{~h}(\mathrm{P}<0.05)$ (Fig. 5B). Only the Chk1-si cells treated with GS developed obvious apoptotic features (Fig. 5C), including nuclear fragmentation. When we examined the mechanism of apoptosis in the Chk1-si transfected SUIT-2 cells after GS treatment, the expression of Bcl-2 was decreased after $24 \mathrm{~h}$ (Fig. 5D). Knockdown of Chk1 using siRNA showed almost the same apoptotic signaling pathway as prexasertib when used in combination with GS (Fig. 4B and C). However, the fact that $\gamma \mathrm{H} 2 \mathrm{AX}$ was not induced in the Control-si-treated GS group is thought to be due to differences in several experimental conditions. The expression of Bcl-2 was also significantly decreased by Chk1-si + GS $(\mathrm{P}<0.05)($ Fig. $5 \mathrm{E})$.

\section{Discussion}

In the present study, the results revealed that combinations of prexasertib and antitumor drugs (GEM or S-1) have a synergistic antiproliferative effect and a combination of prexasertib and GS (GEM and S-1) was the most effective in SUIT-2 cells. Furthermore, the combination of all three drugs (prexasertib 


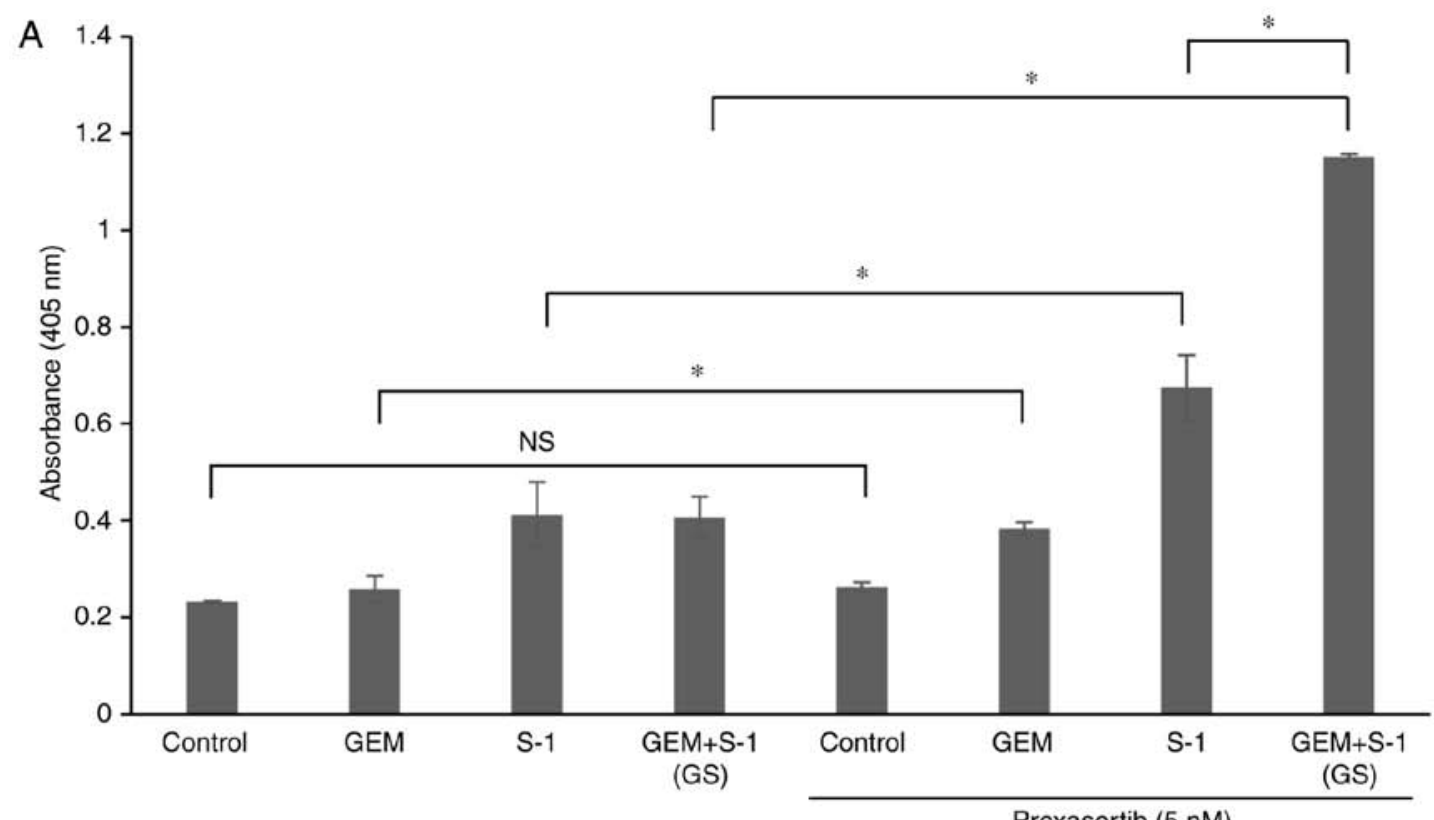

B

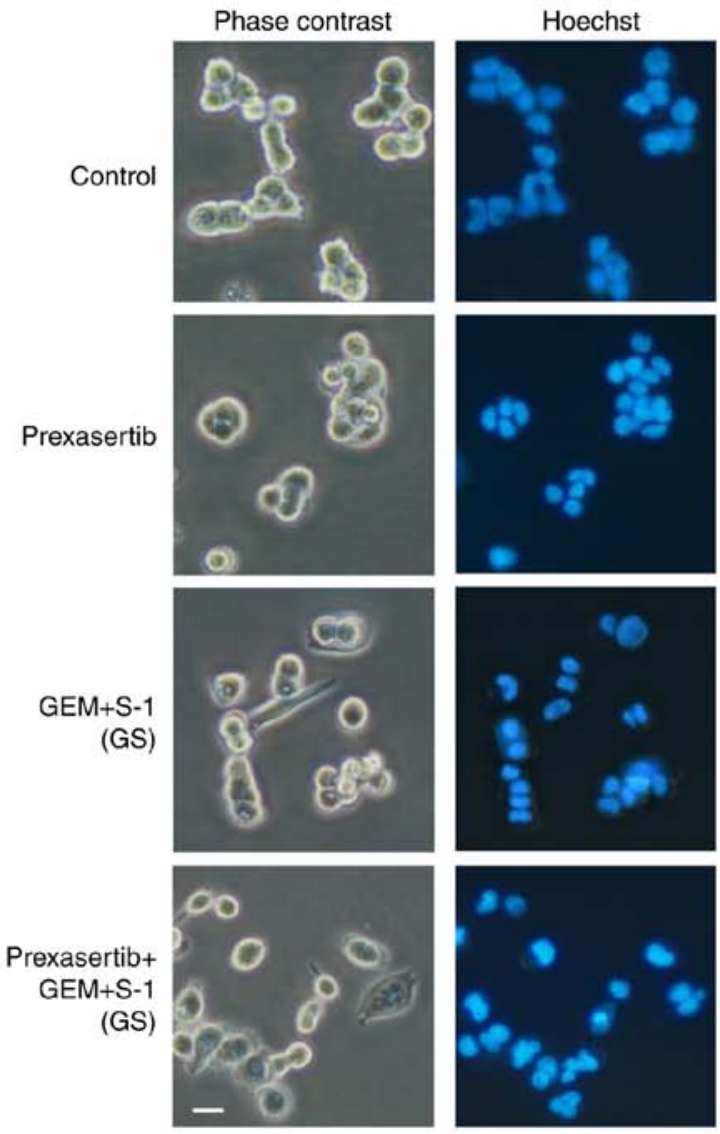

Figure 3. Prexasertib + GEM + S-1 increased apoptotic cell death. (A) SUIT-2 cells were treated with prexasertib $5 \mathrm{nM}$ and/or GEM $0.3 \mathrm{ng} / \mathrm{ml}$ and/or S-1 $0.2 \mu \mathrm{g} / \mathrm{ml}$ for $72 \mathrm{~h}$. Values shown are the mean $\pm \mathrm{SD}$. ${ }^{*} \mathrm{P}<0.05$ indicates a significant difference. NS, not significant. (B) Analysis of morphological changes induced by prexasertib + GEM + S-1 at $72 \mathrm{~h}$. After staining the cells with Hoechst 33342, morphological changes were analyzed under a fluorescence microscope or assessed by phase contrast microscopy. The scale bar indicates $10 \mu \mathrm{m}$. GEM, gemcitabine; GS, GEM + S-1 combined treatment.

+ GS) induced apoptotic cell death through the suppression of Bcl-2.

DNA checkpoints are activated by DNA damage, and serve to arrest the cell cycle and catalyze DNA repair. DNA checkpoints are controlled by two major signaling pathways, namely, the ATM/Chk2/p53 pathway and the ATR/Chk1/Cdc25A pathway (26). In many cancers, the ATM/Chk2/p53 pathway is impaired; therefore, Chk1 inhibitors are expected to selectively induce mitotic cell death in cancer cells (26). Preclinical studies in solid tumor and blood cancer models have shown that prexasertib as a single agent or in combination with other agents has antitumor activity both in vitro and 
A

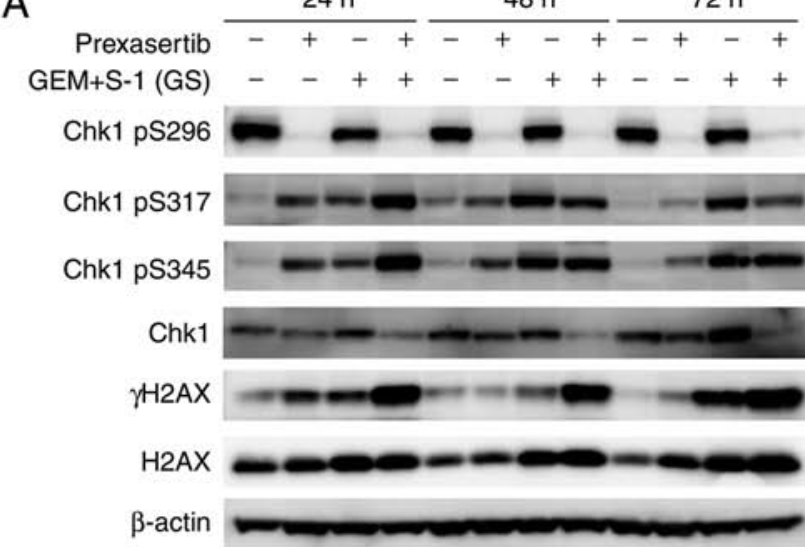

C

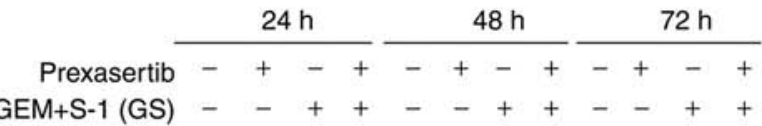
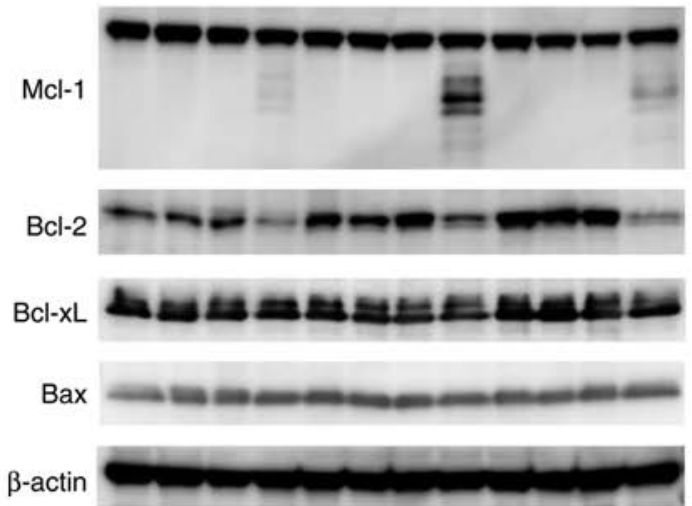

B

Prexasertib $\frac{24 \mathrm{~h}}{-+-+++-+++-+} \frac{48 \mathrm{~h}}{-+++4}$
GEM+S-1 (GS) - $-++\ldots++\ldots++$

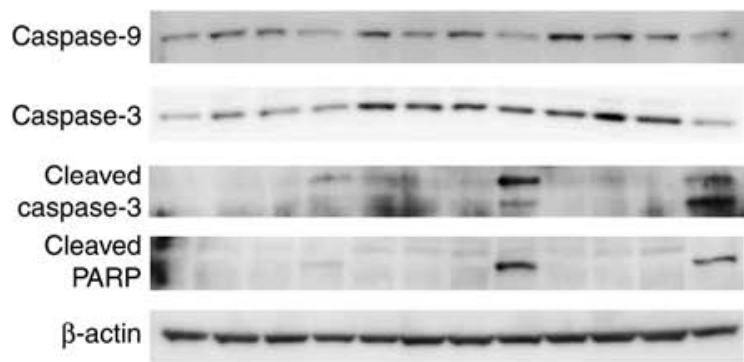

D

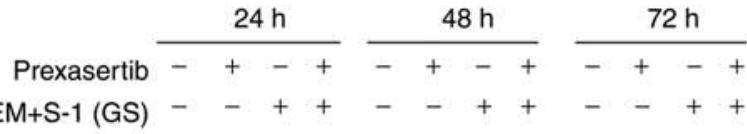

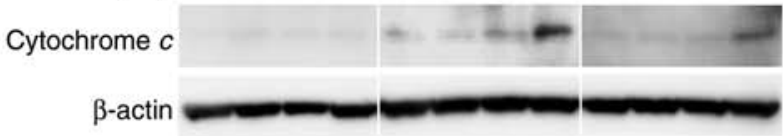

E

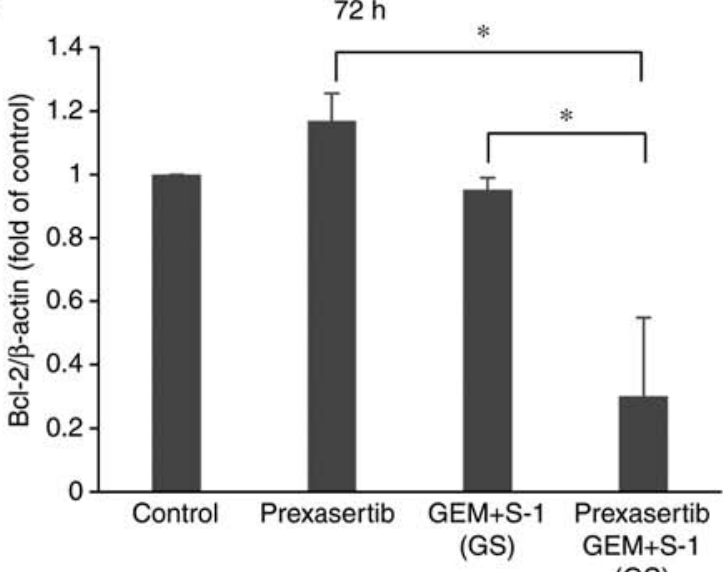

(GS)

Figure 4. (A) Effect of prexasertib, GEM + S-1 and prexasertib + GEM + S-1 on Chk1 (pS296, pS317, pS345), Chk1, $\gamma \mathrm{H} 2 \mathrm{AX}$, and H2AX levels in SUIT-2 cells. (B and C) Western blot analysis revealed the levels of caspase 9, caspase 3, and PARP and Bcl-2 family. (D) Release of cytochrome $c$ from mitochondria was detected. SUIT-2 cells were treated for 24,48 , and $72 \mathrm{~h}$ either without (control) or with prexasertib, GEM + S-1, or prexasertib + GEM + S-1. (E) Level of expression of $\mathrm{Bcl}-2$ at $72 \mathrm{~h}$ normalized to that of $\beta$-actin $(\mathrm{Bcl}-2 / \beta$-actin) and reported as the fold change compared with the control value. The relative band intensities of Bcl-2 and $\beta$-actin were quantified using densitometric analysis. Values are expressed as the mean \pm SD of three independent experiments. ${ }^{*} \mathrm{P}<0.05$ indicates a significant difference. GEM, gemcitabine; GS, GEM + S-1 combined treatment; Chk1, checkpoint kinase 1; PARP, poly(ADP-ribose) polymerase.

in vivo (23,27-30). Dysregulation of Chk1-dependent replication and checkpoint control by prexasertib is thought to be an extremely efficient approach to the induction of apoptosis in cancer cells. We previously showed that both GEM and S-1 led to the increased phosphorylation of Chk1 (15). Therefore, the effects of both drugs can be enhanced by combining them with an effective Chk1 inhibitor. The results showed a synergistic effect for each drug. Although prexasertib + GS increased the phosphorylation of Chk1-S317 and Chk1-S345, which are DNA damage markers, prexasertib strongly suppressed the phosphorylation of Chk1-S296, which is the most important autophosphorylation site for the activation of Chk1 (26). Previous reports have also shown that prexasertib suppresses the autophosphorylation of Chk1-S296 $(23,27,29)$.
Although there have been several reports that show that GEM in combination with other Chk1 inhibitors has a strong antitumor effect $(20,31,32)$, this study is the first to show that the combined effect with $\mathrm{S}-1$, which is an oral fluorinated pyrimidine drug, led to high Chk1 inhibition and efficiently induced apoptosis. It has also been reported that the Chk1 pathway is involved in the resistance mechanism of 5-FU (33). In addition, our results showed that prexasertib + GS had a stronger effect than prexasertib + GEM or prexasertib + S-1, and this may be due to greater induction of Chk1 phosphorylation by GS than by GEM or S-1 alone.

Few studies have conducted a close examination of the mechanism of apoptosis via combinations of a Chk1 inhibitor and antitumor drugs. Therefore, we examined the Bcl-2 family, 
A

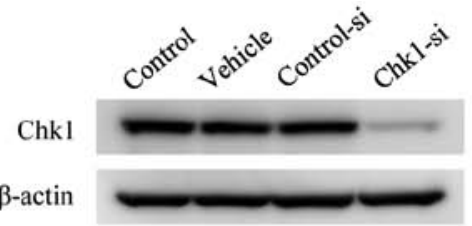

C Phase contrast Hoechst
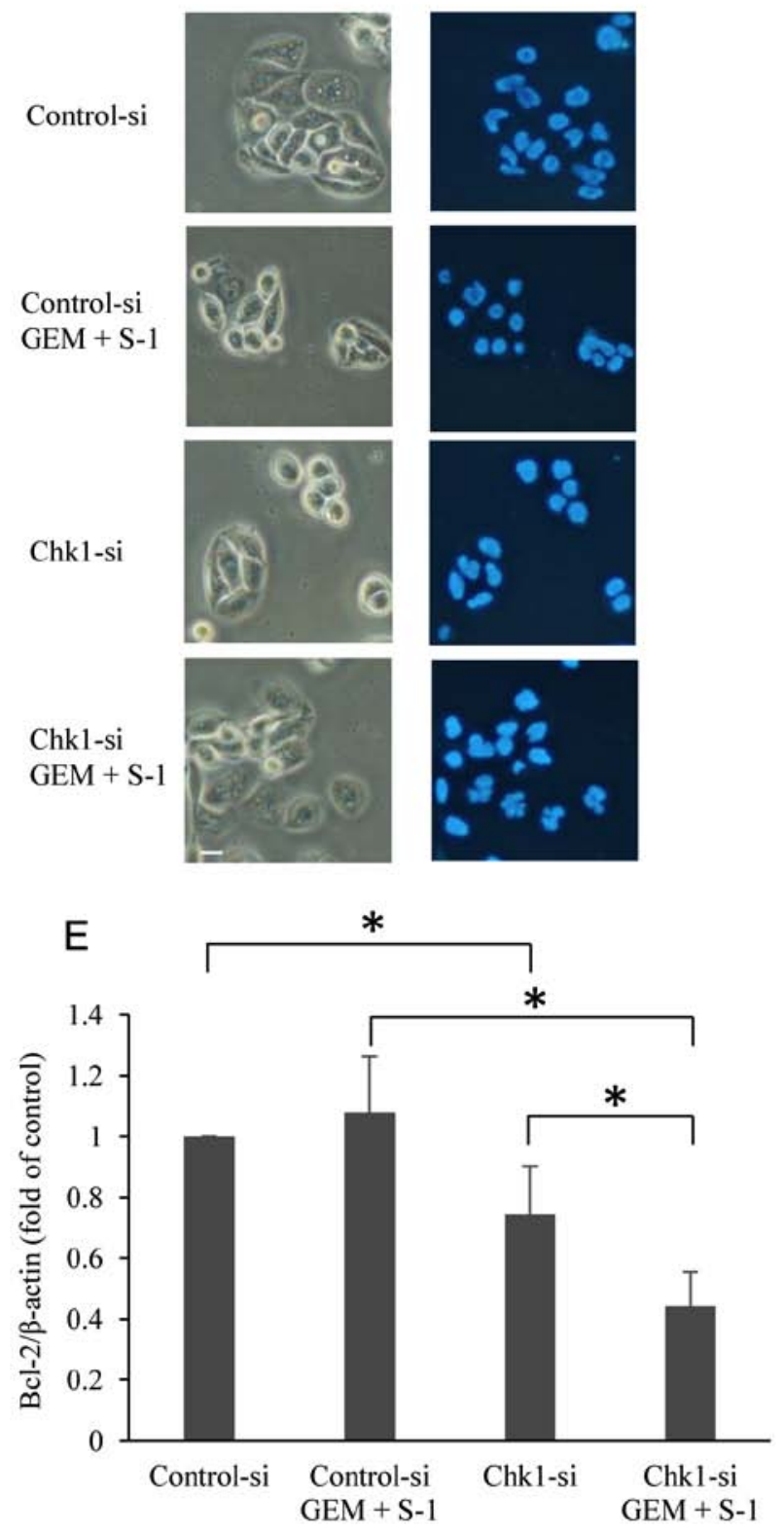

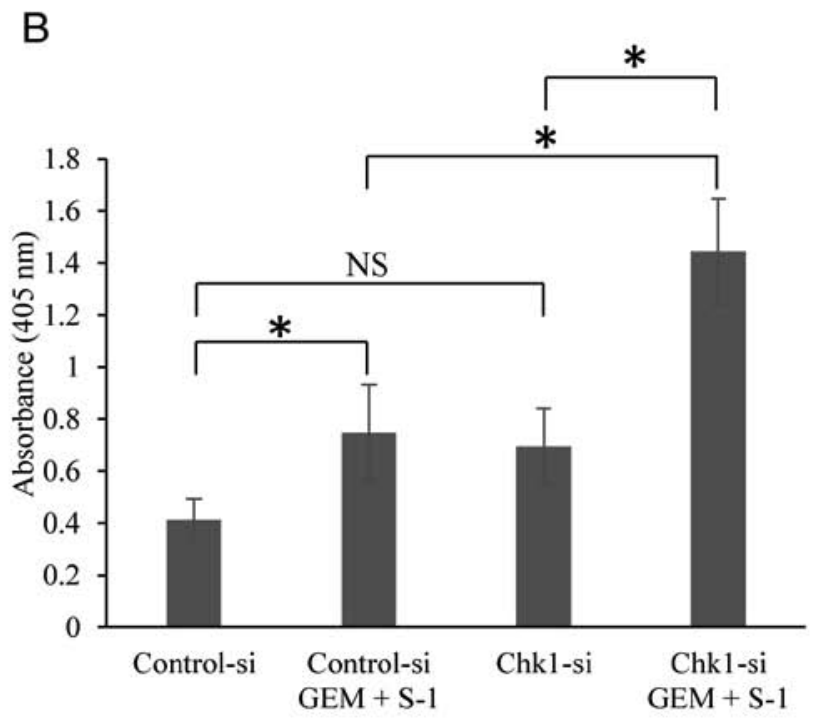

D

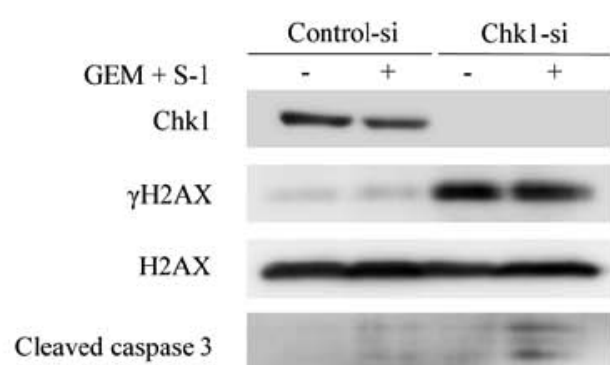

Cleaved PARP

Mcl-1

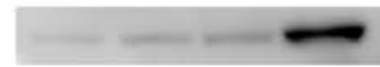

$\mathrm{Bcl}-2$

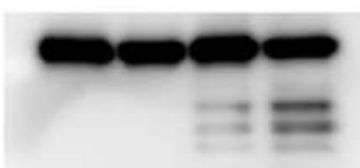

Bcl-xL

BAX

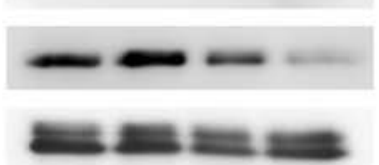

$\beta$-Actin

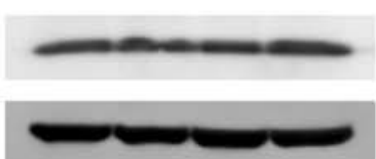

Figure 5. Effects of Chk1-specific siRNA on combination treatment with GEM + S-1 (GS). (A) SUIT-2 cells were transfected with vehicle, non-silencing siRNA (Control-si) and Chk1-specific siRNA (Chk1-si). After transfection, the levels of expression of Chk1 and $\beta$-actin were analyzed by western blotting. (B) SUIT-2 cells were treated with GEM + S-1 (GS) for $24 \mathrm{~h}$ after transfection of Control-si or Chk1-si. The extent of apoptosis was quantified by Cell Death ELISA. Values shown are the mean \pm SD. ${ }^{*} \mathrm{P}<0.05$ indicates a significant difference. (C) After staining of the cells with Hoechst 33342 , morphological changes were analyzed under a fluorescence microscope, or assessed by phase contrast microscopy. The scale bar indicates $10 \mu \mathrm{m}$. (D) Western blot analysis shows changes in the expression of apoptosis-related factors in SUIT-2 cells treated with GEM + S-1 (GS) for $24 \mathrm{~h}$ after transfection of Control-si or Chk1-si. (E) Level of expression of Bcl-2 normalized to that of $\beta$-actin (Bcl-2/ $\beta$-actin) and reported as the fold change compared with the control value. The relative band intensities of Bcl-2 and $\beta$-actin were quantified using densitometric analysis. Values are expressed as the mean \pm SD of three independent experiments. ${ }^{*} \mathrm{P}<0.05$ indicates a significant difference. NS, not significant; GEM, gemcitabine; GS, GEM + S-1 combined treatment; Chk1, checkpoint kinase 1.

which has been a target of drug discovery in recent years. Western blot analysis showed that prexasertib + GS suppressed $\mathrm{Bcl}-2$. Bcl-2 is located in mitochondria and controls apoptosis by inhibiting the release of cytochrome $c$ (34). The selective
Bcl-2 inhibitor venetoclax (ABT-199) has already shown a strong effect on refractory chronic lymphocytic leukemia in combination with rituximab in a phase III trial (35). It has been reported that $\mathrm{Bcl}-2$ expression is intimately involved in 
the induction of apoptosis in pancreatic cancer cells (36). In human colon cancer cell lines, it has been reported that the sensitivity of anticancer agents depends on the expression level of Bcl-2 (37); thus, the detailed mechanism and effective combinations with existing antitumor drugs must be investigated. We have not clarified the detailed relationship between the Chk1 and Bcl-2 mechanisms in the synergistic effect of prexasertib + GS; therefore, it is necessary to investigate the correlation. In addition, the combination of low concentrations of the three agents caused apoptosis efficiently; therefore, we did not investigate the mechanism for the two-drug combinations (prexasertib + GEM or prexasertib $+\mathrm{S}-1$ ). We plan to investigate the two-drug combinations (prexasertib + GEM or prexasertib $+\mathrm{S}-1$ ) in future research. Similarly, only one cell line was used in the present study, and therefore multiple pancreatic cancer cell lines must be utilized in future research.

Furthermore, we showed that prexasertib + GS increased the levels of cleaved Mcl-1. Mcl-1 is a member of the Bcl-2 family and has an antiapoptotic effect. It has been reported that Mcl-1 cleaved by caspase 3 in non-small cell lung cancer cells treated with antitumor drugs triggers apoptosis and the cleavage by caspase partially impairs the antiapoptotic activity of Mcl-1 (38). Drug research targeting Mcl-1 has been progressing in recent years, but the detailed mechanisms of Mcl-1 during apoptosis induced by antitumor drugs are still unknown and further investigation is required.

The standard regimens currently used worldwide as chemotherapy for metastatic pancreatic cancer are FOLFIRINOX or GEM + nab-paclitaxel $(39,40)$. However, FOLFIRINOX frequently induces grade 3 adverse events and GEM + nab-PTX results in a high frequency of peripheral neuropathy and neutropenia. Thus, even though both regimens have antitumor effects in pancreatic cancer, they can be administered only to patients with a good performance status due to their high toxicity. In Japan, GS is used for perioperative chemotherapy or in the elderly for pancreatic cancer $(41,42)$. Regarding cholangiocarcinoma, GS has been proven not to be inferior to GEM and cisplatin (GC) therapy, which are worldwide standard treatments (43). Because GC has severe side effects, such as vomiting and acute kidney injury, a regimen of either GC or GS can be selected according to the patient's situation. In addition to pancreatic cancer, the combined effect of prexasertib + GS in cholangiocarcinoma must be examined.

Several Chk1 inhibitors have been developed, and the results of several clinical trials have been reported $(18-22,44,45)$. However, none of the drugs can be used in clinical settings for various reasons, such as poor efficacy and high toxicity. Prexasertib is currently under development and shows single-agent activity against ovarian cancer and squamous cell carcinoma $(46,47)$. However, it frequently leads to grade 4 neutropenia. Therefore, it is desirable to combine existing antitumor drugs and prexasertib to create regimens that have fewer side effects via using lower doses.

Prexasertib enhanced the antitumor effect of GEM + S-1 through the induction of apoptosis in pancreatic cancer cells with downregulation of anti-apoptotic Bcl-2 protein. Prexasertib could be a useful agent to enhance the effect of GEM or fluorinated pyrimidine drugs, which are standard drugs for the treatment of pancreatic cancer.

\section{Acknowledgements}

Not applicable.

\section{Funding}

No funding was received.

\section{Availability of data and materials}

All data generated or analyzed during this study are included in this published article.

\section{Authors' contributions}

YMo designed the study, performed the experiments, analyzed the data, and wrote the manuscript. KT coordinated the experiments and the writing of the manuscript. OT supervised the research and experiments. AT coordinated the data analysis and the writing of the manuscript. $\mathrm{KW}, \mathrm{MH}$, and $\mathrm{TH}$ collected and reviewed the data and coordinated the writing of the manuscript. YMa coordinated the scientific research and the writing of the manuscript. All authors read and approved the final manuscript and agree to be accountable for all aspects of the research in ensuring that the accuracy or integrity of any part of the work are appropriately investigated and resolved.

\section{Ethics approval and consent to participate}

Not applicable.

\section{Patient consent for publication}

Not applicable.

\section{Competing interests}

The authors declared that they have no competing interests.

\section{References}

1. Burris HA III, Moore MJ, Andersen J, Green MR, Rothenberg ML, Modiano MR, Cripps MC, Portenoy RK, Storniolo AM, Tarassoff $\mathrm{P}$, et al: Improvements in survival and clinical benefit with gemcitabine as first-line therapy for patients with advanced pancreas cancer: A randomized trial. J Clin Oncol 15: 2403-2413, 1997.

2. Shirasaka T, Shimamato Y, Ohshimo H, Yamaguchi M, Kato T, Yonekura K and Fukushima M: Development of a novel form of an oral 5-fluorouracil derivative (S-1) directed to the potentiation of the tumor selective cytotoxicity of 5-fluorouracil by two biochemical modulators. Anticancer Drugs 7: 548-557, 1996.

3. Tatsumi K, Fukushima M, Shirasaka T and Fujii S: Inhibitory effects of pyrimidine, barbituric acid and pyridine derivatives on 5-fluorouracil degradation in rat liver extracts. Jpn J Cancer Res 78: 748-755, 1987

4. Fukui Y, Oka T, Nagayama S, Danenberg PV, Danenberg KD and Fukushima M: Thymidylate synthase, dihydropyrimidine dehydrogenase, orotate phosphoribosyltransferase mRNA and protein expression levels in solid tumors in large scale population analysis. Int J Mol Med 22: 709-716, 2008.

5. Shirasaka T, Nakano K, Takechi T, Satake H, Uchida J, Fujioka A, Saito H, Okabe H, Oyama K, Takeda S, et al: Antitumor activity of $1 \mathrm{M}$ tegafur-0.4 M 5-chloro-2,4-dihydroxypyridine-1 M potassium oxonate (S-1) against human colon carcinoma orthotopically implanted into nude rats. Cancer Res 56: 2602-2606, 1996. 
6. Shirasaka T, Shimamoto $\mathrm{Y}$ and Fukushima M: Inhibition by oxonic acid of gastrointestinal toxicity of 5-fluorouracil without loss of its antitumor activity in rats. Cancer Res 53: 4004-4009, 1993.

7. Sasako M, Sakuramoto S, Katai H, Kinoshita T, Furukawa H, Yamaguchi T, Nashimoto A, Fujii M, Nakajima T and Ohashi Y: Five-year outcomes of a randomized phase III trial comparing adjuvant chemotherapy with S-1 versus surgery alone in stage II or III gastric cancer. J Clin Oncol 29: 4387-4393, 2011.

8. Koizumi W, Narahara H, Hara T, Takagane A, Akiya T, Takagi M, Miyashita K, Nishizaki T, Kobayashi O, Takiyama W, et al: S-1 plus cisplatin versus S-1 alone for first-line treatment of advanced gastric cancer (SPIRITS trial): A phase III trial. Lancet Oncol 9: 215-221, 2008

9. Ohtsu A, Baba H, Sakata Y, Mitachi Y, Horikoshi N, Sugimachi K and Taguchi T: Phase II study of S-1, a novel oral fluorophyrimidine derivative, in patients with metastatic colorectal carcinoma. S-1 cooperative colorectal carcinoma study group. Br J Cancer 83: 141-145, 2000

10. Okamoto I, Yoshioka H, Morita S, Ando M, Takeda K, Seto T, Yamamoto N, Saka H, Asami K, Hirashima T, et al: Phase III trial comparing oral S-1 plus carboplatin with paclitaxel plus carboplatin in chemotherapy-naïve patients with advanced non-small-cell lung cancer: Results of a west Japan oncology group study. J Clin Oncol 28: 5240-5246, 2010.

11. Kubota K, Sakai H, Katakami N, Nishio M, Inoue A, Okamoto H, Isobe H, Kunitoh H, Takiguchi Y, Kobayashi K, et al: A randomized phase III trial of oral S-1 plus cisplatin versus docetaxel plus cisplatin in Japanese patients with advanced non-small-cell lung cancer: TCOG0701 CATS trial. Ann Oncol 26: 1401-1408, 2015.

12. Ueno H, Ioka T, Ikeda M, Ohkawa S, Yanagimoto H, Boku N, Fukutomi A, Sugimori K, Baba H, Yamao K, et al: Randomized phase III study of gemcitabine plus S-1, S-1 alone, or gemcitabine alone in patients with locally advanced and metastatic pancreatic cancer in Japan and Taiwan: GEST study. J Clin Oncol 31: 1640-1648, 2013.

13. Uesaka K, Boku N, Fukutomi A, Okamura Y, Konishi M, Matsumoto I, Kaneoka Y, Shimizu Y, Nakamori S, Sakamoto $\mathrm{H}$, et al: Adjuvant chemotherapy of $\mathrm{S}-1$ versus gemcitabine for resected pancreatic cancer: A phase 3, open-label, randomised, non-inferiority trial (JASPAC 01). Lancet 388: 248-257, 2016

14. Yoshizawa J, Takizawa A, Takeuchi O, Hiraku O, Sasaki K, Morimoto Y, Atsuda K, Inoue G, Suzuki Y, Asanuma F and Yamada Y: Experimental study of combination therapy with S-1 against pancreatic cancer. Cancer Chemother Pharmacol 64 1211-1219, 2009

15. Morimoto Y, Takeuchi O, Takizawa A, Yoneyama H, Asanuma F, Suzuki Y, Atsuda K and Yamada Y: Effect of a combination of $\mathrm{S}-1$ and gemcitabine on cell cycle regulation in pancreatic cancer cell lines. Anticancer Drugs 23: 505-514, 2012.

16. Jackson SP and Bartek J: The DNA-damage response in human biology and disease. Nature 461: 1071-1078, 2009.

17. Dent P, Tang Y, Yacoub A, Dai Y, Fisher PB and Grant S: CHK inhibitors in combination chemotherapy: Thinking beyond the cell cycle. Mol Interv 11: 133-140, 2011.

18. Li T, Christensen SD, Frankel PH, Margolin KA, Agarwala SS Luu T, Mack PC, Lara PN Jr and Gandara DR: A phase II study of cell cycle inhibitor UCN-01 in patients with metastatic melanoma: A California cancer consortium trial. Invest New Drugs 30: 741-748, 2012.

19. Webster JA, Tibes R, Morris L, Blackford AL, Litzow M, Patnaik M, Rosner GL, Gojo I, Kinders R, Wang L, et al Randomized phase II trial of cytosine arabinoside with and without the CHK1 inhibitor MK-8776 in relapsed and refractory acute myeloid leukemia. Leuk Res 61: 108-116, 2017.

20. Sausville E, Lorusso P, Carducci M, Carter J, Quinn MF Malburg L, Azad N, Cosgrove D, Knight R, Barker P, et al: Phase I dose-escalation study of AZD7762, a checkpoint kinase inhibitor, in combination with gemcitabine in US patients with advanced solid tumors. Cancer Chemother Pharmacol 73: 539-549, 2014

21. Wehler T, Thomas M, Schumann C, Bosch-Barrera J, Viñolas Segarra N, Dickgreber NJ, Dalhoff K, Sebastian M, Corral Jaime J, Alonso M, et al: A randomized, phase 2 evaluation of the CHK1 inhibitor, LY2603618, administered in combination with pemetrexed and cisplatin in patients with advanced nonsquamous non-small cell lung cancer. Lung Cancer 108 : $212-216,2017$
22. Karp JE, Thomas BM, Greer JM, Sorge C, Gore SD, Pratz KW, Smith BD, Flatten KS, Peterson K, Schneider P, et al: Phase I and pharmacologic trial of cytosine arabinoside with the selective checkpoint 1 inhibitor Sch 900776 in refractory acute leukemias. Clin Cancer Res 18: 6723-6731, 2012.

23. King C, Diaz HB, McNeely S, Barnard D, Dempsey J, Blosser W, Beckmann R, Barda D and Marshall MS: LY2606368 causes replication catastrophe and antitumor effects through CHK1-dependent mechanisms. Mol Cancer Ther 14: 2004-2013, 2015.

24. Wagenpfeil S, Treiber U and Lehmer A: Statistical analysis of combined dose effects for experiments with two agents. Artif Intell Med 37: 65-71, 2006

25. Hirata K, Horikoshi N, Aiba K, Okazaki M, Denno R, Sasaki K, Nakano Y, Ishizuka H, Yamada Y, Uno S, et al: Pharmacokinetic study of S-1, a novel oral fluorouracil antitumor drug. Clin Cancer Res 5: 2000-2005, 1999.

26. Goto H, Izawa I, Li P and Inagaki M: Novel regulation of checkpoint kinase 1: Is checkpoint kinase 1 a good candidate for anti-cancer therapy? Cancer Sci 103: 1195-1200, 2012

27. Ghelli Luserna Di Rorà A, Iacobucci I, Imbrogno E, Papayannidis C, Derenzini E, Ferrari A, Guadagnuolo V, Robustelli V, Parisi S, Sartor C, et al: Prexasertib, a Chk1/Chk2 inhibitor, increases the effectiveness of conventional therapy in B-/T- cell progenitor acute lymphoblastic leukemia. Oncotarget 7: 53377-53391, 2016.

28. Zeng L, Beggs RR, Cooper TS, Weaver AN and Yang ES: Combining Chk $1 / 2$ inhibition with Cetuximab and radiation enhances in vitro and in vivo cytotoxicity in head and neck squamous cell carcinoma. Mol Cancer Ther 16: 591-600, 2017.

29. Lowery CD, VanWye AB, Dowless M, Blosser W, Falcon BL Stewart J, Stephens J, Beckmann RP, Bence Lin A and Stancato LF: The checkpoint kinase 1 inhibitor prexasertib induces regression of preclinical models of human neuroblastoma. Clin Cancer Res 23: 4354-4363, 2017.

30. Brill E, Yokoyama T, Nair J, Yu M, Ahn YR and Lee JM: Prexasertib, a cell cycle checkpoint kinases 1 and 2 inhibitor, increases in vitro toxicity of PARP inhibition by preventing Rad51 foci formation in BRCA wild type high-grade serous ovarian cancer. Oncotarget 8: 111026-111040, 2017.

31. Barnard D, Diaz HB, Burke T, Donoho G, Beckmann R, Jones B, Barda D, King C and Marshall M: LY2603618, a selective CHK1 inhibitor, enhances the anti-tumor effect of gemcitabine in xenograft tumor models. Invest New Drugs 34: 49-60, 2016

32. Montano R, Thompson R, Chung I, Hou H, Khan N and Eastman A: Sensitization of human cancer cells to gemcitabine by the Chk1 inhibitor MK-8776: Cell cycle perturbation and impact of administration schedule in vitro and in vivo. BMC Cancer 13: 604, 2013.

33. Fujinaka Y, Matsuoka K, Iimori M, Tuul M, Sakasai R, Yoshinaga K, Saeki H, Morita M, Kakeji Y, Gillespie DA, et al: ATR-Chk1 signaling pathway and homologous recombinational repair protect cells from 5-fluorouracil cytotoxicity. DNA Repair (Amst) 11: 247-258, 2012

34. Yang J, Liu X, Bhalla K, Kim CN, Ibrado AM, Cai J, Peng TI, Jones DP and Wang X: Prevention of apoptosis by Bcl-2: Release of cytochrome c from mitochondria blocked. Science 275: 1129-1132, 1997

35. Seymour JF, Kipps TJ, Eichhorst B, Hillmen P, D'Rozario J, Assouline S, Owen C, Gerecitano J, Robak T, De la Serna J, et al: Venetoclax-Rituximab in relapsed or refractory chronic lymphocytic leukemia. N Engl J Med 378: 1107-1120, 2018.

36. Dong J, Zhao YP, Zhou L, Zhang TP and Chen G: Bcl-2 upregulation induced by miR-21 via a direct interaction is associated with apoptosis and chemoresistance in MIA $\mathrm{PaCa}-2$ pancreatic cancer cells. Arch Med Res 42: 8-14, 2011.

37. Hakata S, Terashima J, Shimoyama Y, Okada K, Fujioka S, Ito $\mathrm{E}$, Habano $\mathrm{W}$ and Ozawa $\mathrm{S}$ : Differential sensitization of two human colon cancer cell lines to the antitumor effects of irinotecan combined with 5-aza-2'-deoxycytidine. Oncol Lett 15: 4641-4648, 2018

38. Wang T, Yang Z, Zhang Y, Zhang X, Wang L, Zhang S and Jia L: Caspase cleavage of Mcl-1 impairs its anti-apoptotic activity and proteasomal degradation in non-small lung cancer cells. Apoptosis 23: 54-64, 2018.

39. Conroy T, Desseigne F, Ychou M, Bouché O, Guimbaud R, Bécouarn Y, Adenis A, Raoul JL, Gourgou-Bourgade S, de la Fouchardière C, et al: FOLFIRINOX versus gemcitabine for metastatic pancreatic cancer. N Engl J Med 364: 1817-1825, 2011. 
40. Von Hoff DD, Ervin T, Arena FP, Chiorean EG, Infante J, Moore M, Seay T, Tjulandin SA, Ma WW, Saleh MN, et al: Increased survival in pancreatic cancer with nab-paclitaxel plus gemcitabine. N Engl J Med 369: 1691-1703, 2013.

41. Motoi F, Ishida K, Fujishima F, Ottomo S, Oikawa M, Okada T, Shimamura H, Takemura S, Ono F, Akada M, et al: Neoadjuvant chemotherapy with gemcitabine and S-1 for resectable and borderline pancreatic ductal adenocarcinoma: Results from a prospective multi-institutional phase 2 trial. Ann Surg Oncol 20: 3794-3801, 2013.

42. Ishii H, Yamashita N, Ueno M, Ohkawa S, Saito AM and Sekimoto M: A randomised controlled trial of gemcitabine hydrochloride plus S-1 combination therapy versus gemcitabine hydrochloride therapy alone in pancreatic cancer patients aged $\geq 75$ years: A study protocol for an open-label randomised feasibility study. BMJ Open Gastroenterol 5: e000187, 2018.

43. Mizusawa J, Morizane C, Okusaka T, Katayama H, Ishii H, Fukuda $\mathrm{H}$ and Furuse J; Hepatobiliary and Pancreatic Oncology Group of the Japan Clinical Oncology Group: Randomized phase III study of gemcitabine plus S-1 versus gemcitabine plus cisplatin in advanced biliary tract cancer: Japan clinical oncology group study (JCOG1113, FUGA-BT). J Clin Oncol 46: 385-388, 2016.
44. Scagliotti G, Kang JH, Smith D, Rosenberg R, Park K, Kim SW, Su WC, Boyd TE, Richards DA, Novello S, et al: Phase II evaluation of LY2603618, a first-generation CHK1 inhibitor, in combination with pemetrexed in patients with advanced or metastatic non-small cell lung cancer. Invest New Drugs 34: 625-635, 2016.

45. Laquente B, Lopez-Martin J, Richards D, Illerhaus G, Chang DZ, Kim G, Stella P, Richel D, Szcylik C, Cascinu S, et al: A phase II study to evaluate LY2603618 in combination with gemcitabine in pancreatic cancer patients. BMC Cancer 17: 137, 2017

46. Lee JM, Nair J, Zimmer A, Lipkowitz S, Annunziata CM, Merino MJ, Swisher EM, Harrell MI, Trepel JB, Lee MJ, et al: Prexasertib, a cell cycle checkpoint kinase 1 and 2 inhibitor, in BRCA wild-type recurrent high-grade serous ovarian cancer: A first-in-class proof-of-concept phase 2 study. Lancet Oncol 19: 207-215, 2018.

47. Hong DS, Moore K, Patel M, Grant SC, Burris HA III, William WN Jr, Jones S, Meric-Bernstam F, Infante J, Golden L, et al: Evaluation of prexasertib, a checkpoint kinase 1 inhibitor, in a phase Ib study of patients with squamous cell carcinoma. Clin Cancer Res 24: 3263-3272, 2018. 